\title{
A Comparison of Japanese and U.S. High-Technology Transfer Practices
}

\author{
ROBERT S. CUTLER
}

\begin{abstract}
The high-technology transfer practices of Japanese and U.S. researchers are described and compared to determine how industrial organizations can make better use of the basic research performed at universities in the United States and abroad.
\end{abstract}

\section{INTRODUCTION}

$\mathrm{M}$ UCH HAS been written about recent Japanese commercial success and its economic impact in international markets. A number of reasons are offered in explanation. One frequently cited is the Japanese ability to assimilate and apply new technologies derived from basic research done in the United States. Another reason is the policy of Japanese companies to develop and produce quality products based on new technology.

In this paper, I present some empirical results and observations which describe the principal ways in which a sample of industrial researchers in Japan and in the U.S. utilize certain new technologies resulting from university research. The findings are from a survey conducted in Japan and the U.S. between October 1986 and December 1987.

I conclude that personal communications and technical collaboration are the key factors in the rapid diffusion of research results in both countries, and that in Japan, government agencies and professional societies take a much more active role in organizing and energizing the civilian technology transfer process than do counterpart organizations in the United States.

\section{The Technology Transfer Survey}

The investigation involved a comparative study of Japanese and U.S. high-technology transfer practices, particularly regarding the utilization of university research in three fields: robotics, biotechnology, and ceramic materials.

The focus was on three fundamental engineering fields where Japanese and U.S. firms appear to be comparable in terms of technological capability. I had read in the press [1] that former attitudes about technology transfer were beginning to shift and, in some new fields, the Japanese were beginning to innovate, rather than import patented technology, and to export and license their latest technology to international markets.

\footnotetext{
Manuscript received March 15, 1988; revised July 21, 1988. The review of this paper was arranged by Editor D. F. Kocaoglu. This work was supported by the Japan-U.S. Educational Commission (Fulbright Foundation) and the Office of Naval Research. This paper was presented at the Symposium on Science in Japan, 155th Annual Meeting of the American Association for the Advancement of Science, San Francisco, CA, Jan. 15, 1989.

The author was with the University of Tokyo, Tokyo, Japan, on leave from the National Science Foundation, Washington, DC 20550

IEEE Log Number 8824315 .
}

During the early part of my nine-month stay in Japan, I recognized the face of the so-called "Japanese miracle," the rapid economic development over the past two decades based on technology. I then set out to investigate and compare the ways in which new technologies are acquired and commercialized in Japan, and hopefully to learn how it is done so well and so fast.

Technology transfer involves many functional as well as cultural factors. When interpreting the differences observed between Japanese and American technology practices, I believe it important to view the Japanese-their institutions and their behaviors-from a cultural perspective.

Simply stated, the Japanese have a different language, a different thought process, and different social and business processes than Americans. To attempt to observe technology separately from its environment is to lose sight of this larger picture. I was soon to discover that there are strong cultural elements in the ways the Japanese acquire, evaluate, and transfer new technology. I elaborate on those elements later.

\section{SCOPE OF SURVEY}

My research in Japan primarily involved a survey of Japanese university and industrial researchers who are working in three high-technology fields. Fifty-five interviews were conducted at twelve universities, nine companies, and at six government R\&D organizations. The parallel survey in the U.S. included 51 researchers at eleven universities, eight companies, and three government organizations. In total, 106 researchers were polled in the two surveys (Fig. 1).

The questions focused on the professional behavior of the researcher himself, rather than on the research per se. The objective was to identify the principal transfer mechanisms used by the particular researcher in Japan or the U.S. and his professional colleagues at universities and other R\&D organizations.

In addition, information was sought about career objectives and hiring practices, awareness of significant research advances, and attitudes toward collaborative arrangements with foreign counterparts.

\section{APPROACH}

First, let me offer the succinct definition of "technology transfer"' which Jacques Bagur of Gulf South Research Institute presented on June 21,1987 , to members of the Federal Laboratory Consortium: "Technology transfer is the process by which knowledge concerning the making or doing 


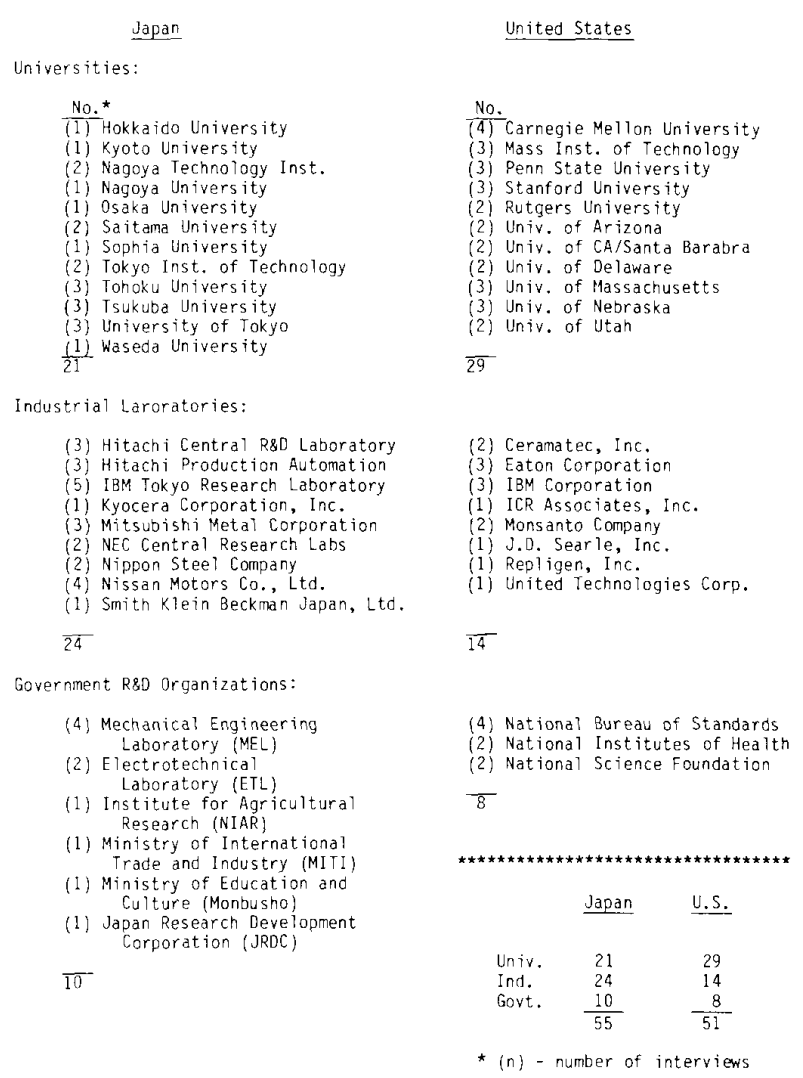

Fig. 1. Survey sample.

of useful things contained within one organized setting is brought into use within another organization context."

The concept of technology transfer which I use in this study consists of several functional mechanisms which are classified into three domains:

- publications-journals, technical reports, trade press;

- patents-invention disclosures, patents, and licenses; and

- people links-meetings, collaborations, joint projects.

These domains are operationally defined by the principal mechanisms used for communicating, facilitating, or otherwise moving the results of university research into industrial application (Fig. 2). The approach supports the multiple factor philosophy, wherein technology transfer is seen as a process involving many functional and environmental factors working in concert.

\section{An Appropriate Research Model}

As a researcher myself, I was compelled to devise an appropriate model and to collect relevant information and data. From the kinds of program evaluation studies we do at the National Science Foundation (NSF), I have learned that a proper evaluation design involves a simple model which describes the principal factors and the relationship of the data to the results. My reasoning for choosing the three domains of the model are as follows.

1) When one attempts to compare research activities,

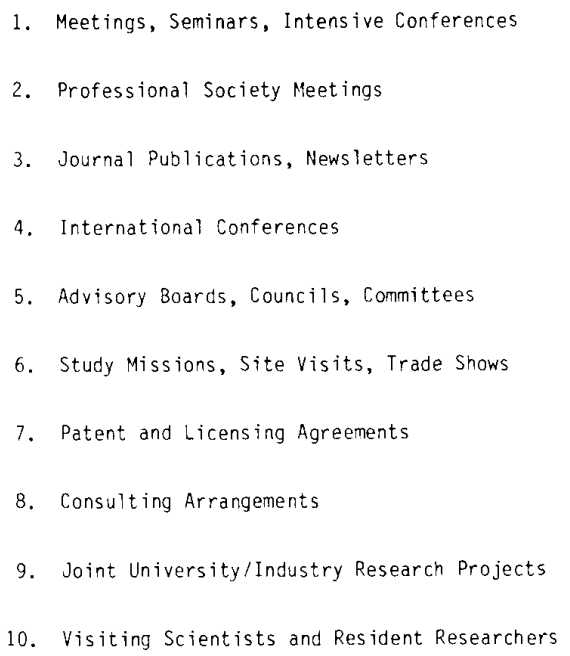

Fig. 2. Principal technology transfer mechanisms.

although there is some professional controversy as to what is significant, it is generally accepted among science policy researchers that the publication of journal articles and citations to those articles in other publications are reasonable measures of scientific advancement and research productivity.

2) Patent counts are now becoming useful to econometricians who study the process of technological innovation. The use of such numbers is less exact than citations to the literature, nonetheless some carefully selected patent statistics reflecting large quantities can be a useful indicator. There is also new interest in university patents because such patents can attract industrial support [2].

3) The third domain of the model is what I call "people links." From talking with several policy analysts before going to Japan, and from my experience as an R\&D engineer in industry and a research administrator at NSF, I have learned that technology transfer also occurs in activities such as professional societies, workshop seminars, and employee mobility.

The three-domain model expresses the notion that technology transfer is more than simply the exchange of technical publications, or the licensing of patents. Rather, the model of the transfer process includes various contact mechanisms and communications activities which essentially are person-toperson linkages. Such mechanisms actually serve to bring the desired technology know-how into actual use.

An interview questionnaire was designed to obtain information from each researcher on the following subjects.

a) Publication activities--which journals are most frequently read and where authored articles were most recently published.

b) Patent activity - whether listed as an inventor on patents issued within the last five years, and whether the patents are licensed or used.

c) People links-whether active in professional society activities, consulting, collaborative work, conferences, and career mobility. 


$$
\text { Japan } \quad \underline{\text { U.S. }}
$$

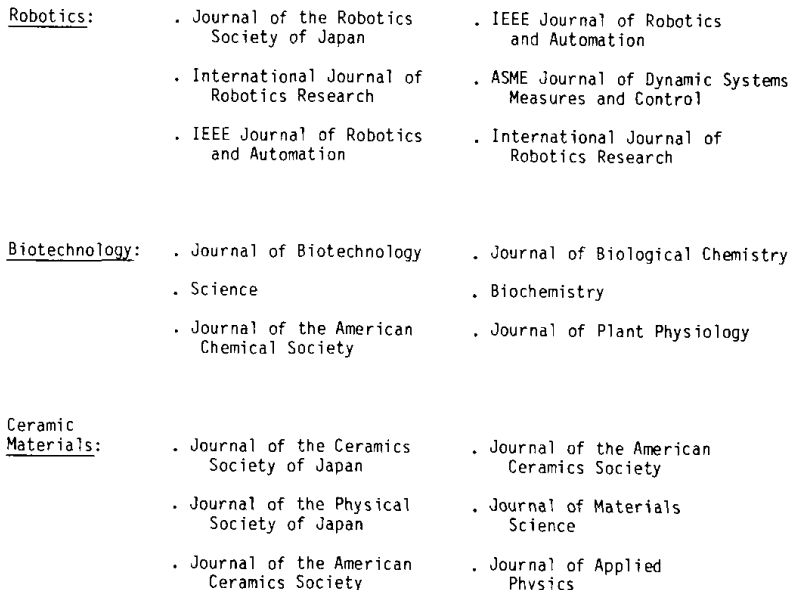

Fig. 3. Principal journals mentioned in survey.

\begin{tabular}{|c|c|c|c|c|c|c|c|c|c|c|c|c|c|c|c|}
\hline & & 981 & & & 982 & & & 1983 & & & 984 & & & 1985 & \\
\hline Institution & App & Pat & Lic & App & Pat & Lic & $\overline{A p p}$ & Pat & Lic & $\overline{A p p}$ & Pat & Lic & $\overline{A p p}$ & Pat & iic \\
\hline OSAKA UNIVERSITY & 2 & 0 & 0 & 5 & 2 & 0 & 10 & 6 & 0 & 11 & 2 & 0 & 9 & 4 & 0 \\
\hline $\begin{array}{l}\text { TOXYO INSTITUTE } \\
\text { OF TECHNOLOGY }\end{array}$ & 6 & 2 & 1 & 8 & 3 & 2 & 15 & 4 & 4 & 19 & 6 & 0 & 12 & 1 & 0 \\
\hline KYOTO UNIVERSITY & 3 & 2 & 0 & 2 & 1 & 0 & 5 & 3 & 0 & 9 & 4 & 1 & 3 & 0 & 1 \\
\hline UNIVERSITY OF TOKYO & 7 & 2 & 1 & 3 & 2 & 1 & 6 & 2 & 2 & 7 & 1 & 2 & 6 & 3 & 4 \\
\hline TOHOKU UNIVERSITY & 6 & 0 & 0 & 7 & 0 & 0 & 3 & 3 & 0 & 2 & 5 & 1 & 2 & 2 & 1 \\
\hline Total: & 24 & 6 & 2 & 25 & 8 & 3 & 39 & $\overline{18}$ & 5 & $\overline{48}$ & $\overline{18}$ & 4 & 32 & $\overline{10}$ & 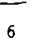 \\
\hline
\end{tabular}

Source: JRDC (5/87)

Fig. 4. Top five Japanese universities' patent activity (applications, patents, licenses) (1981-1985).

\section{FINDINGS}

Based on an analysis of the surveys ${ }^{1}$ conducted in Japan and in the United States, the following comparative results were reported.

\section{Publications}

- In Japan nearly all (94 percent) of the researchers surveyed were able to read and write in English, while in the U.S. very few (4 percent) of the Americans interviewed admitted any technical competence in the Japanese language.

- In Japan a majority of those researchers surveyed $(85$ percent) published and read English language journals articles as well as those in Japanese, while in the U.S. few

${ }^{1}$ Survey sample $(n=106)$ consists of 55 Japanese and 51 U.S. researchers. The population it represents would be hard to describe fully, but I hope is an important part of the university, industry, and government R\&D organizations performing advanced research in the fields of robotics, biotechnology, or ceramic materials, between October 1986 and December 1987 (see Fig. 1).
( 9 percent) said they read any translated Japanese journal articles in their field (Fig. 3.).

- In Japan journal publications do not necessarily contain new work, while most U.S. journal editorial policies insist upon new and original work only.

\section{Patents}

- In Japan few university professors (14 percent) hold patents, while in the U.S. nearly 46 percent of the university researchers surveyed do.

- In Japan, between 1981 and 1985, the number of university patents reported to the Japanese Society for the Promotion of Science (JSPS) by the top five universities increased from 24 to 32 patents (66 percent), while licensing agreements increased from 2 to 6 (Fig. 4.).

- In the U.S., between 1981 and 1985, the number of patents reported by the top five research universities increased from 122 to 177 (45 percent). Licensing for the same five years increased from 53 to 96 (81 percent) (Fig. 5). 


\begin{tabular}{|c|c|c|c|c|c|c|c|c|c|c|c|c|c|c|c|}
\hline \multirow[b]{2}{*}{ Institution } & \multicolumn{3}{|c|}{1981} & \multicolumn{3}{|c|}{1982} & \multicolumn{3}{|c|}{1983} & \multicolumn{3}{|c|}{1984} & \multicolumn{3}{|c|}{1985} \\
\hline & $\overline{D C 1}$ & $p_{a t}$ & {$[\overline{i c}$} & DCT & Pat & $\overline{\text { Lic }}$ & $\overline{\mathrm{DC} T}$ & Pat & Lit & $\overline{D C 1}$ & Pát & Lic & $\overline{\mathrm{BC}} \mathrm{C}$ & Pat & Tic \\
\hline UNIV. OF CALIFORNIA & 234 & 41 & 6 & 308 & 49 & 11 & 214 & 48 & 9 & 285 & 51 & 12 & 320 & 51 & 18 \\
\hline $\begin{array}{l}\text { MASS. INSTITUTE } \\
\text { OF TECHNOLOGY }\end{array}$ & 155 & 51 & 10 & 161 & 61 & 12 & 147 & 51 & 18 & 122 & 56 & 20 & 121 & 52 & 13 \\
\hline STANFORO & 112 & 12 & 19 & 147 & 7 & 22 & 196 & 14 & 25 & 124 & 35 & 30 & 134 & 38 & 35 \\
\hline UNIV. OF WISCONSIN & 41 & 18 & 13 & 69 & 18 & 6 & 83 & 27 & 11 & 82 & 23 & 17 & 77 & 30 & 12 \\
\hline UNIV. OF WASHINGTON & 28 & 0 & 5 & 21 & 4 & 2 & 38 & 2 & 2 & 47 & 4 & 11 & 62 & 6 & 16 \\
\hline & - & - & - & - & - & - & 一 & - & - & - & - & - & - & — & 一 \\
\hline Total: & 570 & 122 & 53 & 706 & 139 & 53 & 678 & 142 & 65 & 660 & 169 & 90 & 714 & 177 & 94 \\
\hline
\end{tabular}

Fig. 5. Top five U.S. universities' patent activity (disclosures, patents, licenses) (1981-1985).

$\begin{array}{lcc} & \frac{\text { Japan }}{(n=27)} & \frac{\text { U.S. }}{(n=22)} \\ \text { Universities: } & 18 \% & 38 \% \\ \text { Industry: } & 17 \% & 57 \% \\ \text { Gov't Labs: } & 33 \% & 61 \%\end{array}$

Fig. 6. Ph.D. ratio in laboratories surveyed.

\section{People Links}

- In Japan 93 percent of the university researchers and 80 percent of the industrial researchers surveyed said they attend technical meetings outside their work location at least twice per month, while in the U.S. 43 percent of the university researchers and 17 percent in industry said they did so.

- In Japan the average proportion of the Ph.D's reported in the work unit (Ph.D. ratio) was 18 percent for the universities, 17 percent for industry, and 33 percent for government labs. In the U.S. the ratios were 38 percent for universities, 57 percent for industry, and 61 percent for government labs (Fig. 6).

- In Japan 62 percent of the high-technology university researchers surveyed and 46 percent of those in industry said they were involved in at least one joint university $/$ industry project. In the U.S. the level was 84 percent for universities and 93 percent for those surveyed in industry.

- In Japan 78 percent said they have worked for their current employer since graduating from college, while 23 percent of those surveyed in the U.S. said they did.

- In Japan 59 percent reported having attended at least one international meeting during the past two years. In the U.S. the proportion was 28 percent.

- In Japan 65 percent of those surveyed said they spent a year or more in the United States or in Europe. In the U.S. 34 percent said that they had spent more than one year abroad; 4 percent had worked in Japan; and 17 percent had visited Japan for brief periods ranging from one to three weeks.

\section{Additional Observations}

- In Japan 83 percent of the researchers surveyed said they were aware of current research advances made by foreigners in their field. In the U.S. only 30 percent said they knew of any.

- In the U.S. the following attitudes and interests were expressed by researchers interviewed regarding the work of Japanese colleagues:

-68 percent of the university researchers, 35 percent of the industrial researchers, and 60 percent of the government researchers acknowledged having had at least one Japanese research colleague or visiting researcher in his laboratory.

-78 percent said that they would welcome some type of research collaboration with an appropriate counterpart in Japan.

-63 percent said they would be willing to work in a laboratory in Japan for an extended period of time. (Most favored four to six months.)

- Among those surveyed in both countries, the mechanisms preferred most for affecting high-technology transfer are:

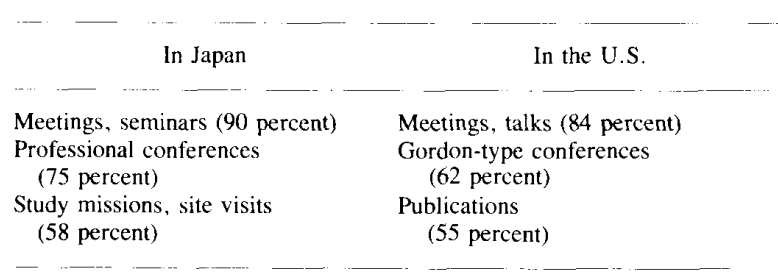

In addition, some two-thirds of the robotics researchers surveyed in Japan said they currently exchange VCR video tape recordings with colleagues in their own country. However, it was not clear how widespread the use of video tape recordings is among U.S. researchers.

\section{Caveat on the Analysis}

Due to limitations in the data and the sampling method used, one should not draw definitive conclusions from this study. However, there are some interesting findings which are more 
suggestive than indicative. Moreover, the concept of technology transfer itself is complex and difficult to define precisely. This is an emerging area requiring more study and analysis.

\section{DisCUSSION}

From the findings outlined above, it is clear there are similarities as well as some important differences in the way technology is transferred between university and industrial researchers in Japan and in the U.S.

In contrast to the kinds of scientific research performed in the U.S., most of the research I observed in Japanese universities can be described more accurately as "fundamental engineering science," rather than basic scientific research. It usually is done in groups rather than by individual investigators, and it consists largely of experimental verification work. However, there are a few senior professors doing some theoretical work at the more basic end of the research process.

\section{Publications}

To describe what the Japanese do differently, first I will discuss journal publications.

The principal sources of basic research information for the Japanese researchers I interviewed are the journal articles published by leading university researchers in the U.S. and in Europe, rather than by other Japanese researchers.

Journal editors in Japan apparently do not insist on publishing only original work. Their journals often consist of progress reports as well as reports on setting up and testing methods of experimentation which may have been published elsewhere. I am told, however, that academic societies in Japan also publish some paper journals (called "Ronbun-shi") which are used to report original research. This practice is related partly to Japanese feelings about originality, ${ }^{2}$ which are quite different from those in the West, and in part, to Japanese research funding practices, particularly in universities which require progress reports to be published.

Japanese engineering researchers work in teams to carry through a particular project, from the initial research stage, through development, to prototyping, and even on to production and marketing. It is difficult to track research advancement via publications, in Japan, because there are no intermediate publication points.

In the U.S., by contrast, a university researcher typically does the fundamental work and then publishes his or her findings in the journal literature. From those publications in the open literature, another researcher picks up the new knowledge and basic ideas which he/she considers to be feasible, carries it through the applied research phase, and again publishes the results either in the journal literature, as a company report, or as a patent disclosure. The industrial R\&D community picks promising projects out of this pool of new technology. In this process, however, users' requirements are rarely cited or integrated into the research design, as often is the case in Japan.

\footnotetext{
${ }^{2}$ The traditional Japanese attitude about originality is one which prefers to follow a pattern rather than to break new ground. In Japanese, the term "learn" (manabu) is derived from "imitate" (maneru) [5].
}

\section{Patents}

Although the proportion of surveyed Japanese professors holding patents is smaller (14 percent) than that of the Americans (46 percent), the top five universities in Japan reported an increase of 66 percent between 1981 and 1985 , and the American top five universities reported a 45 percent increase.

The difference between the two groups in the number of patents acquired stems largely from the traditional belief in Japan that universities are primarily for the teaching of students, rather than for commercializing research results which is the domain of industry. However, this picture is now changing.

Although the number of Japanese university inventions since 1981 is smaller than that for U.S. universities, the JSPS data show a remarkable increase in the licensing of those patents during the past five years.

This increase appears to reflect the recent shift in the patent policy of both countries (since 1978 and 1980) which authorized universities and research laboratories to promote inventions resulting from government funded projects. Both in Japan and the U.S. there are programs now in place to assist university professors to transfer their inventions to commercial use. The Japan Research Development Corporation (JRDC) is the agency responsible for promoting the transfer of university patents to industry. In the U.S. there is no central government responsibility for this activity, rather each research university has its own patent licensing office.

\section{People Links}

I observed throughout this study that the most preferred and also the most effective technology transfer mechanisms are "people intensive," rather than "paper intensive."

This conclusion became clear to me from the amount of time (two-thirds) the researchers said they devote to exchanging new ideas by participating in talks, meetings, and working with leading colleagues, as compared to the remaining onethird of their time spent reading, extracting or preparing new information for publication or for patents. This allocation of time appears to be as true in the United States as it is in Japan, at least for the three high-technology fields surveyed.

Apparently there are strong personal needs for face-to-face discussions leading to bench-to-bench collaboration in order to better communicate new complex ideas from one person to another, and then to utilize them elsewhere in the research lab or in another organization or institutional setting. I conclude that high-technology transfer is largely a "contact sport": meeting with people, carrying new ideas forward, and joining individual efforts toward a common goal.

The rapid transfer of university research to industrial technology also requires the necessary know-how which is a skill attribute of a researcher [3]. In tracing the transfer paths within the fields of robotics, biotechnology, and ceramic materials, in both countries, I find a similarity in the preferential use of person-to-person contacts for obtaining substantive information. Many of these links involve longterm collaborative work between university and industrial researchers. Examples of successful transfers of university 
research to industrial applications can be found in computervision robotics, genetic engineering, and functional ceramics.

If one is attempting to compare the principal technology transfer practices observed in the two countries, three significant factors which underlie the Japanese $R \& D$ system are worth mentioning. They are attitudes about cooperative research, the "old-boy" network, and R\&D management styles.

\section{Japanese Technology Transfer and Cooperative Research}

Japanese companies achieve effective utilization of hightechnology research and its transfer between laboratory and production by holding many more technical meetings on an industry-wide basis than American companies do. Professor Thomas Eagar of M.I.T. observed that "there is not just technology transfer within a company in Japan, but also between companies, and companies and universities, through the many meetings of the various professional societies" [4].

I do not believe there is such a system in the U.S. which pools, analyzes, and disseminates current information on international research activities as effectively as the Japanese system does.

The topics discussed at many of these meetings include more technical content and detail than is common in the U.S. In addition, major research laboratories become familiar with the work at other labs, resulting in rapid dissemination of new results and less duplication of effort. The meetings also permit researchers to communicate very effectively their knowledge of work outside of Japan.

There are a number of reasons why the Japanese system works. One is the strong leadership of the university professors who serve as committee chairmen. There are strong ties between these professors and their former students that do not seem to exist in the United States.

Several of the robotics engineers interviewed in Japan showed me video tapes documenting their current experiments and the work of their colleagues abroad. This low-cost highly effective audiovisual reporting mechanism is yet another example of the way Japanese researchers rapidly exchange current research results.

\section{The Japanese Old-Boy Network}

The process was described by several speakers at a seminar on high-technology competitiveness held by the Japan Technology Transfer Association in Tokyo on March 13, 1987. That discussion helped to crystallize what I discovered during my four dozen interviews in Japan.

Japanese industry has two powerful assets: a cohesive national policy on technology development and a scientific "old-boy" network, with links to practically every board room and laboratory in the country. The government spends nearly one-third of its R\&D budget (20 percent of total R\&D spending) at universities and at government research institutes, and nearly all of this activity is centrally coordinated through government committees and the scientific "old-boy" network.

Here is how the two circles of power work. Perhaps you have noticed that Japanese companies seem to sell similar products, so much so that it looks like they must be collaborating on the designs and specs. That is because hightech Japan is a small country and the top engineers in the companies know each other. For that matter, so do the company presidents, who most likely went to the same university at the same time. When one company starts something new, the president calls his friends to discuss it.

Japanese companies do not suffer from the not-inventedhere syndrome, that attitude which stifles ideas from external sources. Instead, they are eager to please their customers and would rather have their people involved in making something better for the marketplace, than in trying to capture all of the profits from a new technology product. In fact, the licensing of patents from other companies and from foreign sources, including many U.S. universities, is widely practiced.

Many foreigners imagine that government officials at the Ministry of International Trade and Industry (MITI) stand over the R\&D stage like grand puppeteers, manipulating private industry at will. This is not the case, particularly because the average MITI officer changes jobs every two years.

MITI's method of influence is through its committees. A mixture of industry leaders, academics, and consumers (users) are selected for dozens of committees on new technology and industry matters, ranging from restructuring a weak industrial sector to organizing a national program for advanced robotics or for manned spaceflight.

Through committee debate, MITI helps industry form a consensus on which areas of new technology it should concentrate on. By this committee method, policy is actually negotiated by industry leaders, so it is accepted naturally by all the companies. That is what I found to be the secret of Japan's cohesive industrial policy: the government acts as the organizer and coordinator of private industry action. Eighty percent of the R\&D funding in Japan comes from private industry, rather than from the government.

\section{R\&D MANAGEMENT}

A final remark about Japanese methods for running research organizations and their methods for decision making.

What I observed closely resembles what Ouchi of UCLA calls "theory Z" [5]. One main feature of Japanese society which Ouchi describes as being essential for the success of each work unit is the great trust that exists between superiors and those who work for them.

One of the best technology transfer practices of Japanese industry is the quality circle, where five to ten workers meet almost daily to discuss possible improvements in their work. This method works in Japan where it serves to give group sanction to innovative departures from the old ways of doing things.

There is a general sense of family solidarity which seems to characterize Japanese endeavor, whether at home, at work, or in professional pursuits. The personal commitment, trust, and desire for cooperation among researchers serves as a glue which keeps the Japanese R\&D organization together. "In Japan it is difficult to move people, but it's easy to move ideas," one Hitachi laboratory director told me.

From an organizational viewpoint, Dimancescu, of the 
Technology \& Strategy Group, observed that "U.S. companies still live in the world of highly compartmentalized functions and responsibilities. Many of these are staffed by people whose labors are rewarded for maintaining a very narrow definition of the task required of them. This behavior generally goes under the rubric of 'division of labor' or 'specialization,' and is valued as desirable ends. In such a cultural environment, information neither travels fast nor necessarily to the right people at the right time. Hence we find an inferior process of tech transfer (in the U.S.) relative to what is observed in Japan" [6].

Japanese companies have been highly effective in applying new concepts of project management which look nothing like what is practiced in the U.S. The Japanese concept of project management starts with the fundamental belief in the coequal importance of all players needed to fulfill a task and continues on with the constant and continuous process of linking these players together horizontally. This procedure goes a long way toward explaining how the Japanese have advanced so rapidly in high-tech fields during the last three decades.

In the U.S. the antitrust laws have required each competing firm to carry on its own industrial research. Technical cooperation not only is limited but is often perceived as unlawful by corporate management. Recently, however, the law has been liberalized to allow certain consortia like MCC, SEMATECH, and the Semiconductor Research Corporation (SRC) to be organized.

Things are different for industrial research in Japan. The government there actively promotes the formation of research associations among leading companies in particular fields for the purposes of developing and transferring new technologies. Patents resulting from these arrangements are pooled for participating companies to use. And there is a remarkably high degree of communication and collaboration between professors at leading Japanese universities and their colleagues who work in competitive companies [7].

\section{How Technology Policies Differ}

One way to classify technology policies is by whether they are diffusion (technology-push) or mission oriented (userpull). For example, technology policy in Germany and Sweden is diffusion oriented, whereas the technology policy in France, England, and the U.S. is mission oriented.

Japanese technology policy, on the other hand, is both mission oriented and diffusion oriented. Like countries in the first group, Japan emphasizes a broadly based capacity for diffusing innovation-related public goods. Like countries in the second group, it also employs coordinated efforts to advance national technological goals. However, Japanese policy differs from the policies of the other nations in two respects. First, in the recent past, Japan was at a far lower level of development than other industrialized nations. Second, the consensus-based government-industry relationship in Japan involves centralized decision making and decentralized implementation. These two factors have led to technology policies that emphasize rapid upgrading of the nation's technological skills, but in a more decentralized and broadly based manner than in the mission oriented countries [8].
There are three basic elements to Japanese technology policy: 1) promoting leading edge industries through tax policy more than direct financial assistance; 2) facilitating technology transfer; and 3) upgrading of the human capital base on a more general, less industry-specific basis.

\section{CONCLUSION}

This study attempts to plow new ground in an uncharted and complex area: the cross-cultural comparison of technology transfer mechanisms used in Japan and in the U.S. The findings are derived from information obtained during an exploratory survey of active researchers in both countries, who were not randomly selected. However, care was taken to avoid undue geographic concentration and institutional bias. The results presented are more indicative than definitive. Nonetheless, I believe they represent technology transfer in the three high-technology fields surveyed.

I conclude that personal communication and technical collaboration are the key factors in the rapid diffusion of hightechnology research results in both countries, rather than the widespread availability of scientific journal literature and recent efforts to promote university patents. The differences observed in practice stem largely from some of the cultural and institutional factors described.

The empirical findings confirm the conventional view that the flow of high-technology information is largely from U.S. university researchers to industrial researchers in Japan. However, the data also show that some of the most advanced ceramics and robotics technology used in the U.S. increasingly is derived from research initiated in Japan.

Journal publication and university patenting are more widely used in the U.S., where university professors both teach and do basic research. Meetings and intensive conferences, however, are by far the most popular mechanism used for technology transfer among those U.S. researchers surveyed.

In Japan the results of university research are utilized primarily in industrial settings. Typically industry uses outside professional meetings and close collaboration as the means for translating the scientific knowledge and new engineering know-how into commercial use.

In the U.S., government agencies support most of the basic and applied research performed at universities primarily for public purposes such as military defense, public health, and space exploration. By contrast, most of the high-technology research in Japan is funded and performed by industrial companies for commercial purposes. Furthermore, Japanese government agencies and professional societies take a more active role in organizing and energizing the civilian technology transfer process than do the counterpart organizations in the U.S.

The present study confirms an earlier conclusion by Herman Bieber [9] that " technology is primarily transferred by people, not via organizational charts or formal reports." This observation, made in 1969 and primarily related to the communication of new technical information within a single organization, also appears to be valid for effecting technology transfer between different institutional and cultural settings, such as for high- 
technology collaboration between university and industrial researchers in Japan and in the U.S.

This study should be of interest to engineering managers and researchers concerned about the nature of technology transfer and how it occurs in Japan and in the U.S.

\section{ACKNOWLEDGMENT}

The author wishes to thank the National Science Foundation for permission to be away for the period of the project. He also wishes to thank S. T. Cutler who contributed in significant ways to the preparation and editing of this paper.

\section{REFERENCES}

[1] J. Pollack, "The patent as trade barrier,"' The New York Times, July 5, 1984.

[2] R. Cutler, "Patents resulting from NSF engineering program," World Patent Inform., vol. 9, no. 1, pp. 38-42, 1987.

[3] F. Rossini et al., "Interdisciplinary research: Current experience in policy and performance," Interdisciplinary Sci. Rev., vol. 8, no. 2, pp. $127-139,1983$

[4] W. Eager, "Technology transfer and cooperative research in Japan,' ONR Far East Scientific Bull., vol. 10, no. 3, 1985

[5] G. Ouchi, Theory Z. Reading, MA: Addison-Wesley, 1981.

[6] D. Dimancescu, Technology \& Strategy Group, Inc., Boston, MA personal communication, April 20, 1988
[7] R. Cutler, "Impressions and observations of science and technology in Japan," Univ. Tokyo, Japan, Rep. to Japan-U.S. Educational Commission (Fulbright Foundation), May 1987

[8] H. Ergas, Technology and Global Industry: Companies and Nations in the World Economy (Nat. Acad. Eng. Series on Technology, Social Priorities). Paris, France: Organisation for Economic Cooperation and Development (OECD), 1987.

[9] H. Bieber, "Technology transfer in practice," IEEE Trans. Eng. Manag., vol. EM-16, no. 4, pp. 144-155, 1969.

\section{BIBLIOGRAPHY}

[10] J. L. Bloom, "Japan enters the world series of technology," The World \& I, pp. 214-223, Sept. 1987.

[11] R. G. Havelock and V. Elder, "Technology transfer in Japan: An exploratory review," Center Productive Use Tech., George Mason Univ., Fairfax, VA, Rep. June 1987.

[12] H. Kobayashi, "Scientific creativity and engineering innovation in Japan," presented at the Symp. Science in Japan, 153rd Annu. Meeting, Amer. Assoc. Advancement Sci., Chicago, IL, Feb. 16, 1987.

[13] R. J. Marcus, "Observations on science in Japan," ONR Far East Scientific Bull., Mar. 1983.

[14] L. S. Peters, "Technical network between U.S. and Japanese industry," Center for Sci. and Tech. Policy, Rensselaer Polytechnic Institute, Troy, NY, Rep., Mar. 1987.

[15] E. A. Vogel, Japan as Number One. Tokyo, Japan: Tuttle, 1980.

[16] R. Cutler, Ed., "Japanese science and technology: The changing institutional framework," in Proc. AAAS Symp., Science in Japan: An update, 153rd Annu. Meet. Amer. Assoc. Advancement Sci. Chicago, IL, Feb. 16, 1987, to be published. 